The type generally used at this time was the encasing of the limb in plaster, with slits for the traction strapping and fixation of the limb to the Thomas splint with plaster bandages. The plasters were always padded and split. Details, with dates and simple diagrams, were well marked on the plaster, and proved most useful. For the upper extremity the " $U$ " plaster, from the nape of the neck and including the forearm, was mostly used, and proved satisfactory. The immobilization of extensive soft-tissue wounds had been advised, but was perhaps not carried out as often as it might have been. Traction for wounds of the knee-joint was occasionally found to have been omitted. The usual faults in plaster work appeared from time to time: carrying the plaster beyond the proximal crease of the palm, so that stiffness of the metacarpo-phalangeal joints and fingers results; lack of instruction to the patients to move the fingers and toes continually; faulty position of the ankle and foot. These faults always seem to be cropping up, and need constant attention. The results are very difficult to correct.

Abdomen.-The treatment evolved in the Middle East was amply confirmed: suture, when possible, rather than resection; exteriorization and colostomy for wounds of the colon and rectum; gastric suction and intravenous therapy as a routine; and retention of cases for a minimum of ten days.

Chest.-Conservative surgery (wound excision and closure of the open pneumothorax), with early aspiration, was the rule, and proved satisfactory. Great relief of dyspnoea was noted after the early aspiration of haemothorax fluid. Many breathless shocked patients were greatly relieved by being propped up, and these cases travel better in ambulances and trains when so positioned. The advantage of treating the shock by the completely recumbent position does not compensate for the serious respiratory embarrassment caused. In only a few cases was full thoracotomy indicated in the forward area.

Head.-At the beginning there was some difference of opinion between the F.S.U. surgeons and the neurosurgeons as to whether the general surgeons should deal with these cases. It was pointed out that in the forward units the general surgeon had no special equipment for this type of work: diathermy was not available; $x$-ray examination was not always possible; and at the time there was only improvised suction. It was therefore accepted that it was better to get patients back to the neurosurgical unit with 48 hours if this was possible, for operation there. The sulphonamides-sulphadiazine when available-were always used.

Maxillo-facial Wounds.-As little as possible was done in the F.S.U.s and C.C.S.s beyond cleaning up, the arrest of haemorrhage, and fixation of the jaw, when necessary, by the dental officer. These cases were then transferred to the maxillo-facial unit.

Burns.-All coagulation treatment was forbidden as first aid. The routine was sulphanilamide and vaselined-gauze dressing. It was confirmed that cases of severe burns travel badly during the first five or six days after injury.

Septic Sores.-During the hot weather there was much manwastage from sores on the exposed areas of the knee, elbow, and forearm regions. Often quite trivial in origin, they became chronic and resistant to treatment if neglected, and frequently meant weeks in hospital. There seemed to be no panacea for them. Unit medical officers were asked to get men with even minor skin abrasions, thorn-pricks, etc., to report sick at once so that they could obtain early treatment.

Whitlows.-It was found necessary to issue an instruction that only the most minor conditions should be treated by unit medical officers. Much time and many bad results are saved by early admission to hospital. Too many midline and inadequate incisions under ethyl chloride were seen in the early stages of the campaign.

Chemotherapy.-It was impressed on all that the sulphonamides are not a substitute for early surgery. These drugs were used prophylactically and therapeutically. To begin with, oral doses at four-hourly intervals had been advised for all wounded. In practice this broke down on the long lines of communication, and the Middle East sulphanilamide label, with the two doses at 8 a.m. and 6 p.m., was adopted. Owing to the universal use of these drugs, both orally and locally, it was impossible to evaluate their effect. The genera impression was that they were of value in retarding the onset" of infection. Also, as compared with the last war, the appearance and general condition of the men in the base hospitals seemed better. Although many wounds were infected the patients did not look so toxic and ill. Sulphanilamide, sulphathiazole, and sulphapyridine were the forms mainly in use for surgical cases. Some sulphadiazine was obtained latterly. Penicillin was not available in this campaign The Penicillin Unit arrived in North Africa in May, 1943, and began investigations in one of the Algiers hospitals.

Anaerobic Infections.-Tetanus: Up to May, 1943, one case of generalized tetanus occurred in a German prisoner-of-war and one case of local tetanus in a British soldier. Both recovered. Gas gangrene: It is regretted that actual figures are not available. Up to May, 1943, there had been under 100 cases. Treatment was by early surgery, large doses of serum, and the sulphonamides.

\section{Some Statistics}

(a) The number of battle casualties operated on in 12 F.S.U.s and 6 C.C.S.s between Nov., 1942, and May 15, 1943, was:total operations, 8,881: deaths, 331 ; mortality, $3.72 \%$. It is interesting to compare these with some figures from the last war. On the Somme in July, 1916, 13 C.C.S.s of the Fourth Army dealt with 14,400 casualties on the first day, 13,306 on the second day, and 8,793 on the third day. The surgical staff of the C.C.S.s had, of course, been reinforced by a considerable number of surgical teams.

(b) Figures from four general hospitals in Algiers for the period Nov., 1942, to Sept., 1943 (wounds of the abdomen, chest, and head), were:

\begin{tabular}{l|c|c|c|c|c|c|c|c}
\hline & Total & $\begin{array}{c}\text { To } \\
\text { Duty }\end{array}$ & $\begin{array}{c}\text { To } \\
\text { Conv. } \\
\text { Depot }\end{array}$ & $\begin{array}{c}\text { Trans. to } \\
\text { Other } \\
\text { Hosp. }\end{array}$ & $\begin{array}{c}\text { To } \\
\text { U.K. }\end{array}$ & Died & $\begin{array}{c}\text { Remain- } \\
\text { ing }\end{array}$ & $\begin{array}{c}\text { Mor- } \\
\text { tality }\end{array}$ \\
\hline $\begin{array}{c}\text { Wounds of } \\
\text { abdomen }\end{array}$ & 287 & 77 & 54 & 14 & 129 & 8 & 5 & $2 \cdot 7 \%$ \\
$\begin{array}{c}\text { Wounds of } \\
\text { chest }\end{array}$ & 599 & 147 & 127 & 72 & 221 & 5 & 27 & $0 \cdot 8 \%$ \\
$\begin{array}{c}\text { Wounds of } \\
\text { head }\end{array}$ & 420 & 129 & 52 & 43 & 170 & 9 & 17 & $2 \cdot 1 \%$ \\
\hline
\end{tabular}

Acknowledgments are gratefully made to the D.M.S. of the British North African Force, Allied Force Headquarters, Major-Gen. Sir E. M. Cowell, and to the D.D.M.S., First Army, Brig. E. W. Wade, for their courtesy and help. Also to Brig. N. Cantlie, D.D.M.S., 5th Corps, for his unfailing interest in the surgical arrangements and the time he gave up to taking me round on all my visits to his area.

\section{INVESTIGATION AND TREATMENT OF ENURESIS IN THE ARMY PRELIMINARY REPORT ON 277 CASES*}

BY

\section{P. L. BACKUS, M.D., C.M.McGill, D.P.M. \\ T/Lieutenant-Colonel, R.A.M.C.}

AND

\section{G. S. MANSELL, M.R.C.S., L.R.C.P. Captain, R.A.M.C.}

As the result of considerable success in the out-patient treatment, since the outbreak of war, of nocturnal enuresis in soldiers by explanation, education, and suggestion, a fuller investigation of the problem has been undertaken in hospital. The findings and results of treatment presented below are based on the clinical examination and treatment of 277 unselected cases of nocturnal enuresis consecutively admitted to a military (psychiatric) hospital during the eight months ending Sept., 1943.

\section{Examination}

A full physical examination by the medical specialist was made at the time of admission. Special examinations were done on 232 cases as follows:

Bladder-function-test Cystometry.-With due preparation and without local anaesthesia, a No. $8 \mathrm{E}$ soft rubber catheter was passed into the bladder. The resistance to its passage was recorded by an arbitrary standard: + indicated practically no resistance; +++ , strong resistance.. The bladder was emptied and boric acid solution at a temperature of approximately $100^{\circ} \mathrm{F}$. was allowed to flow into it at a pressure of $20 \mathrm{~cm}$. of water. The base-line was taken as $1 \mathrm{~cm}$. below the level of the pubic arch as the patient lay on the table. The apparatus used was a simple graduated glass container held on an adjustable stand. Fixed levels were maintained by moving the head of the stand up and down. A pressure of $20 \mathrm{~cm}$. was chosen, as being just above that required to bring about an initial stimulus to micturate. This was confirmed by our preliminary tests and is quoted by standard works on physiology : " $18 \mathrm{~cm}$." (Sampson Wright, 1940). At this level of pressure, flow was allowed to continue until the patient, having been previously warned, intimated a desire to micturate, when the flow was immediately stopped. A volume reading was taken (see Table I). The patient was then encouraged to relax the bladder by increased control of the external sphincter muscles and an endeavour to create a negative pressure

*A paper read at a meeting of Army psychiatrists held at York in July, 1943. 
in the abdomen. This was reinforced by strong suggestion that the bladder was relaxing and getting bigger. When desire lessened or disappeared the flow of solution was allowed to proceed until a second stimulus occurred. A second arrest of flow was made and a volume reading was taken. This procedure was carried out a third time. These two latter readings are recorded as volumes under voluntary relaxation, and were taken at $20 \mathrm{~cm}$. water-pressure in practically all cases. Two final volume readings called distension readings were then made under $40 \mathrm{~cm}$. and $60 \mathrm{~cm}$. water-pressure respectively. In a few càses pressure was raised to 70 and $80 \mathrm{~cm}$. Volume readings above $600 \mathrm{c.cm}$. were taken in only a few instances. The ability to retain the solution under different pressures was noted, and was recorded on an arbitrary basis: - represented a leakage under $20 \mathrm{~cm}$..pressure; \pm , a leakage under $60 \mathrm{~cm}$. pressure; + , a leakage with catheter removed but controllable; ++ , good control. At the end of the test the catheter was removed while the bladder was still full and the patient was asked to get off the table, walk across the room, and empty his bladder.

Psychological Examination.-On admission a preliminary psychological examination was made. Special attention was given to the history of the complaint. Periods of remission and relapse were investigated for psychological factors. A personality assessment was recorded at the end of the examination.

\section{Findings}

Anamnesis.-The youngest patient was 14 years of age ; the oldest 45 . Over $50 \%$ of the patients were of the ages of 18 to 23 inclusive. The average was 21.33 years. The intelligence score based on the matrix test ranged from S.G. I to V. The mean fell in the S.G. III + group. The reference of cases for treatment undoubtedly showed selection. Length of service presented no important factor. Medical category was: "A," $80.15 \%$; "B," $10.83 \%$; "C," $9.02 \%$. Bed-wetting at the time of admission was present in all but four cases. Frequency and urgency appeared in $82.67 \%$, and precipitancy in $31.77 \%$. Dysuria was complained of in only $4.4 \%$.

There was a history of the main complaint-namely, nocturnal enuresis-since infancy in $75.81 \%$. Of these, $82.81 \%$ had had no remission: though they had many free nights there was no sustained period of freedom. . The remaining $17.19 \%$ had varying periods of freedom-several months and more. Approximately half of these cases relapsed during a nonservice period. The other half relapsed during military service, and the relapse was attributed by the patient to Service conditions. Among the remainder - that is, $24.19 \%$ of the whole group - the complaint developed at varying periods in life ; $58 \%$ occurred before and $42 \%$ after enlistment. In presenting these percentages no attempt is made to argue for psychosomatic relations; clinical findings only are recorded.

In the order of their importance the chief factors contributing to the persistence or onset of the symptoms were as follows. In the non-Service group: lack of any training; domestic difficulties in the home and feelings of insecurity related thereto; the so-called " broken home," such as separation of the parents ; accidents and operations; sexual traumata or anxiety ; the death of one or both parents ; and air raids during childhood. In the group that appeared during Service life, failure to adapt to barrack-room life, regimentation, battle experience, accidentsespecially injury to the external genitals-and operations were given as the cause of the complaint. $43.32 \%$ showed no gross emotional factor, but presented evidence of lack of proper care and training in their difficulties. Definite sexual factors were elicited in a remarkably small number of cases. Masturbation guilt was evident in only three: Of the 125 patients who were married only four gave a history of being affected by the marriage. Promiscuity and fear of venereal disease precipitated an attack in one and a relapse in another two. Punishment for the complaint was incurred in only $14 \%$ of the cases.

The school history of the group was a little above the average. The work history was quite the average for the personality type. A history of organic illness was reported in only a small number. There were no cases of overt abnormality of sexuality. Family histories presented very little of importance. A history of enuresis in parent or sibling was admitted in only $21 \%$ of cases.

\section{Physical Examination}

Physical examination by the medical specialist revealed no abnormality in $92.06 \%$ of cases. Of the remaining $7.94 \%$, genito-urinary disease was present as a chronic nephritis and as acute cystitis in one each and as a chronic prostatitis in one. There were four cases of stricture, apparently congenital, as emphasized by Winsbury-White (1941). Disease of the central nervous system presented one case of disseminated sclerosis. The remaining complaints were of an apparently unrelated type -namely, bronchitis, dyspepsia, and "rheumatism." Spina bifida occulta, as an incomplete development of the neural arches of the lower lumbar and sacral regions, was seen in only 13 out of 104 cases routinely $x$-rayed. In none of these was there any evidence of the symptom-complex known as myelodysplasia.

The Bladder-function Test.-The measure of resistance to the passing of a No. $8 \mathrm{E}$ rubber catheter varied from practically no resistance $( \pm)$ in 17 cases, + in 51 cases, ++ in 141 cases, to the very resistant $(+++)$ in 9 cases. In addition actual obstruction to passage occurred in 14 cases; 10 of these were negotiated by an olive-tipped or coudé gum-elastic catheter or a silver catheter. Four cases had to be sent to hospital for dilatation of a definite stricture. There was no serious complaint about the procedure. Only two refused examination.

Volume readings at the point at which the first stimulus to micturate occurred ranged from $30 \mathrm{c.cm}$. to $750 \mathrm{c.cm}$. the former that of a very small bladder, the latter that of a case of early schizophrenia. Of the series $50 \%$ reacted to a volume stimulant between 100 and $250 \mathrm{c.cm}$. (see Table II).

Table I presents the volume readings of five different cases to illustrate individual findings. Case No. 98 had a small bladder with good initial relaxation. Case No. 79 had a small and very sensitive bladder. His frequency was always severe. Case No. 114 showed a fair average initial relaxation with good powers of voluntary relaxation. Case No. 46 had a bladder of average size but very sensitive. Case No. 163 had a large bladder with a large initial capacity and good powers of voluntary relaxation.

TABLE I.-Volume Readings of 5 Different Types of Case

\begin{tabular}{|c|c|c|c|c|c|c|}
\hline \multirow{3}{*}{$\begin{array}{l}\text { Case } \\
\text { No. }\end{array}$} & \multirow{3}{*}{ Type of Bladder } & \multicolumn{3}{|c|}{$20 \mathrm{~cm}$. Pressure } & \multicolumn{2}{|c|}{ Distension } \\
\hline & & \multirow{2}{*}{$\begin{array}{l}1 \text { st } \\
\text { Stmn. }\end{array}$} & \multicolumn{2}{|c|}{$\begin{array}{l}\text { Voluntary } \\
\text { Relaxation }\end{array}$} & \multirow{2}{*}{$40 \mathrm{~cm}$} & \multirow{2}{*}{$60 \mathrm{~cm}$. } \\
\hline & & & $\begin{array}{l}\text { 2nd } \\
\text { Stmn. }\end{array}$ & $\begin{array}{l}\text { 3rd } \\
\text { Stmn. }\end{array}$ & & \\
\hline $\begin{array}{r}98 \\
79 \\
114 \\
46 \\
163\end{array}$ & 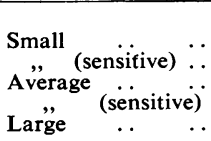 & $\begin{array}{l}\text { c.cm. } \\
160 \\
40 \\
250 \\
70 \\
370\end{array}$ & $\begin{array}{l}\text { c.cm. } \\
170 \\
70 \\
320 \\
110 \\
460\end{array}$ & $\begin{array}{l}\text { c.cm. } \\
.180 \\
80 \\
370 \\
140 \\
560\end{array}$ & $\begin{array}{l}\text { c.cm. } \\
230 \\
260 \\
450 \\
370 \\
650\end{array}$ & $\begin{array}{l}\text { c.cm. } \\
270 \\
300 \\
540 \\
600\end{array}$ \\
\hline
\end{tabular}

TABLE II.-Volume Readings of the Series

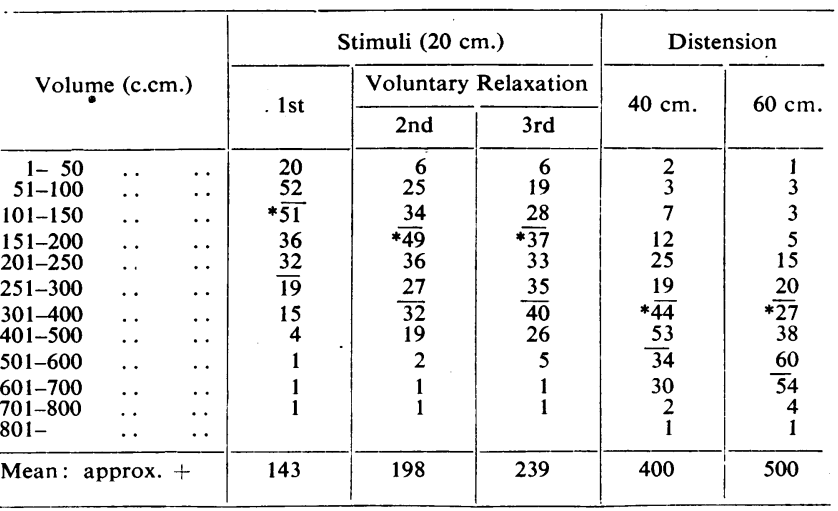

$* 50 \%+$ fall in between the heavy lines.

It will be observed that all patients showed some powers of voluntary relaxation after the initial stimulus. In sensitive bladders this was small, but under pressure the ultimate reading was much the same. Table II gives the volume readings of the entire series within $50 \mathrm{c.cm}$. Very few readings were taken beyond $600 \mathrm{c.cm}$. Only one reached $800 \mathrm{c.cm}$., and this was in an early experimental case. This volume was attained under voluntary relaxation with $34 \mathrm{~cm}$. water-pressure. It is of 
interest to note that this patient had previously been under hypnotic suggestion for bladder relaxation.

Waves in pressure-flow that were synchronous with respiration were often noted. However, in a number of other cases 39 were definitely recorded; more frequent waves appeared as the flow continued, and became more evident as the point of toleration was approached. It was felt that if apparatus of greater sensitivity were used further cases would have shown these rapid rhythmic waves. These waves are described by Denny-Brown and Robertson (1933), and are considered to be uninhibited bladder contractions, after the work of McLellan (1939).

The measure of sphincter control showed leakage under $20 \mathrm{~cm}$. pressure in $1.29 \%$, under $60 \mathrm{sm}$. pressure in $10 \%$ with the catheter out but able to arrest the flow in $9.48 \%$, and good control in $71.13 \%$. Cystoscopy was done in 130 cases, and there was no report of any serious bladder disorder. It is not likely that abnormal cases would be referred to us for treatment. A pyelogram taken in 14 cases showed no important abnormality.

\section{Psychiatric Examination}

In the psychiatric study of the series it was found convenient to divide the cases into six main personality types according to the outstanding characteristics of each. As must be expected, there was a considerable admixture of two or more types. The largest group-namely, $48.01 \%$-fell into what might be called a timid, immature, dependent, often frustrated type. Some of these showed definite schizoid trends. They came from the so-called "broken home" situations, or from homes where there had been much emotional stress in early life. On the whole, this group revealed marked evidence of "love deprivation" in childhood; a considerable number, however, showed strong "mother fixation." They nearly all gave a history of bed-wetting since infancy, and without remission. In other words, their bladders had wept for them in all their difficulties, while they themselves had refused or failed to grow up. If members in, this group were allowed to go on leave while in hospital they reacted badly, and almost invariably relapsed when at home. The next largest group-namely, 27.07\%were of quite an average type of personality. They presented no important emotional stress in their history of childhood or later life. They, too, were largely chronic bed-wetters. It is of special interest to note that a great majority of these patients showed a considerable degree of real indifference to their trouble. Superficially they appeared anxious for treatment, but on deeper investigation the indifference became evident. They required much firmness in treatment to get them to make a serious attempt to help themselves. Having slept in wet diapers all their lives, they appeared to feel no great need for a change. The third group-10.49\%-were those of a reaction type showing compensatory aggression. The fourth-6.14\%-were what might be called pure aggressives; the fifth-5.77\%-were essentially psychopathic personalities, and in some cases gave a psychotic family history. The remaining small group of $2.52 \%$ were predominantly obsessional in type.

\section{Treatment}

By the time the preliminary investigations were completed the patients had already been placed on suitable waking regimes. Fluids were prohibited after 6 p.m. The first move in active treatment was to get the patient to make as frank a statement as possible about his attitude towards his complaint. Following this, in terms easily understood by him, a careful explanation was given of bladder function and control. This was supplemented by a sketch on paper or by the simple device of interlocking the fingers of the two hands to represent the bladder wall. This was related to normal development and control in the average individual. It was conceded that a child might take three or four years to attain full control, and so it wás understood that the patient might not achieve this in a night or two. That a prolonged lack of control had built up an attitude in which the patient had become hardened to his complaint was acknowledged; but, in view of his expressed wish to attain control and as he had an adult mind to bring to bear upon the problem, success was most definitely expected.
The aim was to achieve normal bladder control, and the consideration of this problem was based upon the known physiology of the bladder.

The aim and emphasis in treatment were all towards bladder control in its various aspects. Negative suggestion was scrupulously avoided. General fears of wetting the bed or finding oneself in a difficult sítuation were purposefully replaced by the positive expectation of holding the water under all circumstances. The bladder-function test formed a valuable practical basis for the discussion of the problem with the patient. A bladder of normal size with satisfactory sphincter control could not be denied. What was still more important was the knowledge that good powers of voluntary relaxation were present. When this could not be denied, emphasis upon a need for greater determination in certain aspects of control was self-evident.

The first exercise was therefore maintenance of sphincter control in the daytime. If the sphincter was weak, exercises in holding the water were carried out. The use of ephedrine as an adjuvant may be tried, but in our experience the results were disappointing. The second exercise was voluntary relaxation of the bladder- " Just as you did in the examination." With every initial urge to micturate, while the sphincter is held, the bladder is made to relax with the assistance of negative abdominal pressure by raising of the diaphragm and by strong auto-suggestion of bladder relaxation. This is best understood by trying it on oneself during a time of need. It was interesting to note how many chronic cases of frequency and urgency showed marked improvement under these exercises. Drugs such as atropine or belladonna may be used, and should be carried to full tolerance. These were also found of indifferent value. A dry mouth was a distinct handicap when the patient was restricted in water intake. Medical treatment has now been largely abandoned because of its doubtful value, which experience is supported by the findings of Browne and Ford-Smith (1941).

Nocturnal control was put on the same basis as day control, and was fortified by auto-suggestion at the time of going to sleep. Fears of accident were replaced by strong suggestion of positive control of the sphincter muscle. A "sleep tight" decision, so far as concerns that muscle, was the routine. The rest of the bladder, however, was expected to relax and to go to sleep just as the rest of the body did. This double suggestion of a tight sphincter and a relaxing bladder was given strong and repeated emphasis. It can with great benefit be made the basis of part of the group therapy for a ward. During subsequent psychiatric interviews this procedure was re-emphasized and the patients' determination stimulated. As soon as evidence of control appeared, the waking times were reduced in number and the procedure of "self-waking" was introduced if needed.

This new instruction was based on the idea that while the conscious mind was asleep the deep or unconscious part of the mind would remain in control. Emphasis was placed upon a determination that the latter would maintain continuous control over the sphincter, so that any attempt to force it open by a contraction of the bladder would result in its reflex closure of still greater intensity, such as occurs normally during the daytime. It was stressed that this increased contraction would persist up to a point of such acute discomfort in the bladder that it would wake the patient up. This, after all, is the normal function. One patient who captured the idea of the importance of this mechanism said that he was always waked by a feeling that a knife was being stuck into his bladder. He never wakened of his own volition before. The aim is so to focus the attention on an increase of bladder tone, so to sensitize the individual to it, that this normal mechanism will operate regularly and without failure. In adults this seems to be a much more useful procedure than the mechanical methods of waking, such as the use of the penile clamp of Baretz (1936) or attempts to condition the patient by use of an electric pad that when wet will ring a bell, as devised by the Mowrers (1938). In these the stimulus comes too late.

Aș treatment proceeded one emphasized the successes and disregarded the failures. Analogies, such as learning to skate, 
were presented in which the ability to stay on one's feet, rather than the number of falls one sustained, was considered an index of achievement: the brook having been leapt once, it could be leapt again. Reference to the presence of any fear before the leap always brought the response, "I would land right in the middle "-and so they do, and get wet on both occasions. Any tendency to relax this determination is evidence of the need for immediate and further psychiatric investigation, and sometimes discipline.

General psychotherapy was given throughout the training. This ranged from simple reassurance and suggestion in the mild and more stable type to "depth therapy" by directive reductive methods in the more severe and unstable cases. The use of hypnosis early in treatment was largely abandoned, and was replaced by systematic education under conscious control. We do not think we achieved anything under hypnosis that we have not achieved since without it. Ancillary treatment in hospital was that of the training wing, to which cases were transferred at an early date. Here they received regular physical, para-military, and diversified occupational training. When day and night control was established, posting to duty was arranged. The necessity for posting some of the men to new units, to avoid embarrassment, was kept in mind.

Difficulties in Treatment.-Difficulties increased with age. Of 60 patients of 30 years and over only one-third went back to duty. The same percentage applies to those of low mental category-namely, S.G. V. Physical category in itself had no material bearing. Chronicity, and especially an associated psychoneurosis, made treatment more difficult. A bladder which showed less than $300 \mathrm{c} . \mathrm{cm}$. capacity with $60 \mathrm{~cm}$. waterpressure was always found most difficult to treat.

\section{Disposal}

Up to Nov. 25, 1943, disposal of the 277 cases of the series was as follows:

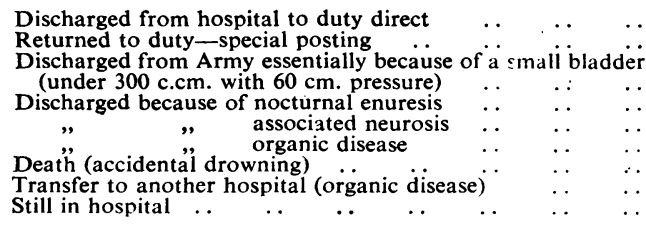

\section{Follow-up}

The follow-up of this series is necessarily very incomplete. Reports have been received from only 40 cases. Of these, 31 are on full duty, efficiently and willingly, with satisfactory bladder control-3 of them after six months; 4 are on light duty, efficiently and willingly, with satisfactory bladder control; 2 have been discharged from the Service; and 3 have been readmitted to hospital for further treatment. In addition a personal communication has been received from 4 more cases, expressing difficulties.

\section{Conclusions}

The older the patient and the poorer the intelligence, the greater the difficulties in treatment. Physical disabilities were negligible in this series, excepting the small bladder. This is in contrast with the $13 \%$ of organic cases mentioned by Stockwell and Smith (1940) in their study of 100 children, and the findings of Winsbury-White (1941) in children in whom cystitis and congenital stricture appeared to be the chief causal factors. Whether the bladder was anatomically or physiologically small was not determined. It is suspected that the size was of ten the result of increase in muscle tone. A followup of these cases, with further cystometric examinations, is needed before any decisions can be reached. A few patients with a small bladder were discharged without much treatment, but the great majority of them were given prolonged and intensive therapy without improvement. One patient remains in hospital, one was discharged after the return to service, and only two, returned to duty, are carrying on.

Even though the history of the enuresis with precipitancy was in nearly all cases similar to that described by Russell Brain (1940) and others in spina bifida occulta, this latter condition appeared to have no effect upon the treatment. Of the 13 cases of spina bifida 8 were returned to duty; the follow-up report of one of these is very satisfactory. Of the 5 dis. charged Category E, 4 had bladders under $300 \mathrm{c.cm}$. capacity and the other was a severe psychoneurotic with low intelligence. This supports the view of Karlin (1935), who considers the defect unimportant unless there is evidence of myelodysplasic change or extensive neural-arch defect.

The problem of treatment, therefore, is essentially psychological. In this series at least $27 \%$ gave no evidence of difficulty other than lack of proper training in childhood. The same difficulty applied to a considerable proportion of the rest, but other factors were also present. Evidence of bladder reaction of the infantile type was seen in many of these cases, as mentioned above. In this group one agrees with Hamill (1940), who considers it "a refusal to accept responsibility," and the Mowrers (1938), who agree with the emphasis of most that it is a continuation of inadequate training. In this type of case in which control appears to be delayed we would agree with Wainwright (1941) that definite treatment towards establishing control should be undertaken. On the other hand, normal inhibitory impulses establish themselves in the vast majority of children, and for other psychological reasons a too early interference or too aggressive training should not be undertaken as his concluding paragraph would suggest. In view of the fact that nearly $50 \%$ of the patients in this series showed immaturity and dependence, psychotherapy directed towards emotional release and maturation is important.

Suitability for treatment in the Army therefore depends on: an age preferably under 30 years, fair intelligence, a bladder of more than $300 \mathrm{c.cm}$. capacity with $60 \mathrm{~cm}$. of water-pressure, and evidence of voluntary powers of relaxation. The personality type should include a reasonably good attitude towards further service. All cases in which the findings are favourable are suitable for out-patient treatment in the unit. An educative routine, as set out above, will produce satisfactory results in a considerable percentage of cases. Where there are no adverse psychiatric factors, admission to a general hospital for routine treatment may be necessary. If this fails, or if psychiatric factors are present, the case should be referred to a psychiatrist with a view to admission to a psychiatric hospital for treatment.

\section{Summary}

A psychiatric study has been made of 277 unselected cases, and a cystometric examination of 232 of these. The average age was 21.33 years; mean intelligence fell in the S.G. III + group. Length of service and medical category were unimportant. $75 \%$ were bedwetters from infancy, and four-fifths of these had had no remission.

Various factors are set out as possible causes: physical disorders appeared in under $8 \%$; spina bifida occulta in just over $10 \%$ of those $x$-rayed; just under $25 \%$ showed small bladders under cystometry, with varying degrees of voluntary control.

Psychiatric investigation presented six main personality types. In order of predominance they were: the timid, the average, the compensatory aggressive, the pure aggressive, the psychopath, and the obsessional.

A form of treatment is outlined and difficulties relating thereto are mentioned.

A report of a small follow-up is given.

Observations and recommendations are set out.

We wish to express thanks to our late commanding officers, Lieut.-Col. J. D. W. Pearce and Lieut.-Col. R. J. Rosie (still C.O. to one of us) for permitting us to do this work and for their great interest and assistance; to Major H. G. McGregor and Capt. S. T. Lewsen, Medical Specialists, for their assistance and co-operation ; to various members of the hospital staff for their unfailing assistance and to Brig. J. R. Rees, whose continued interest and encouragement have kept us on the job in the midst of other somewhat arduous duties. We wish also to thank Brig. J. S. McCombe for permission to publish this paper.

$$
\text { REFERENCES }
$$

Baretz, L. H. (1936). Urol. cutan. Rev., 40, 321.

Brain, W. R. (1940). Diseases of Nervous System, Oxf. Med. Publ., p. 654, London.

Browne, R. C., and Ford-Smith, A. (1941). British Medical Journal, 2, 803.

Denny-Brown, D., and Robertson, E. G. (1933). Brain, 56, 179.

Hamill, R. C. (1940). Diseases of the Nervous System, 1, 272.

Karlin, I. W. (1935). Amer. J. Dis. Child., 49, 125.

McLellan, F. C. (1939). The Neurogenic Bladder, pp. 101, 146, Springfield, III Mowrer, O. H. and W. M. (1938). Amer. J. Orthopsychiat.. 8, 436.

Stockwell, L., and Smith, C. K. (1940). Amer. J. Dis. Child., 59, 1013

Wainwright, S. P. (1941). J. med. Ass. Alabama, 10, 408.

Winsbury-White, H. P. (1941). Lancet, 2, 331.

Wright, S. (1940). Applied Physiology, Oxf. Med. Publ., p. 235, London. 